\title{
Measuring Fibrosis: Is Seeing Really Believing?
}

\author{
Tuyet A. T. Nguyen $\cdot$ Richard K. Sterling
}

Published online: 23 June 2012

(C) Springer Science+Business Media, LLC 2012

\section{Introduction}

Chronic liver disease is a rising global health problem. However, despite vast advances in medical technology, liver biopsy remains the gold standard in assessing disease severity [1]. Biopsy was historically utilized solely for diagnostic purposes; however, with the advent of therapeutic options, biopsy is now additionally utilized in therapeutic decision making and determining prognosis. However, the procedure itself is not without complications and limitations, and patients are reluctant to undergo multiple biopsies during treatment. This has fueled efforts in developing non-invasive methods to measure fibrosis. Early detection of fibrosis allows for identification of patients who require therapy to prevent evolution to cirrhosis. In a recent systematic review by Smith and Sterling [2], non-invasive methods (clinical demographics, serum biomarkers, imaging modalities, breath tests, and complex models) used either alone or in combination were reported. Many non-invasive measures are shown to detect cirrhosis, but are not established in differentiating between stages of fibrosis. Each seems to have its own advantages and disadvantages. Of the imaging techniques, ultrasound holds the most promise due to its widespread availability.

T. A. T. Nguyen $\cdot$ R. K. Sterling $(\square)$

Division of Gastroenterology, Hepatology and Nutrition, Department of Internal Medicine, Virginia Commonwealth University School of Medicine, MCV Box 980341, Richmond, VA 23298-0341, USA

e-mail: rksterli@vcu.edu

R. K. Sterling

Division of Infectious Diseases, Department of Internal Medicine, Virginia Commonwealth University School of Medicine, Richmond, VA, USA

\section{Ultrasound-Based Measures of Fibrosis}

Ultrasound is relatively inexpensive and widely available. Early investigations have focused on the diameter, flow, waveform, and undulation of the three major vessels (the portal vein, hepatic vein and the hepatic artery). Few studies however, focus on distinguishing significant fibrosis (METAVIR stage $\geq$ F2) from those with less fibrosis (F0-F1), important in determining time to initiate antiviral therapy (Table 1) [3-13].

Calculations based on the aforementioned parameters include arterio-porto ratio (A/P ratio), hepatic vein transit time (HVTT), and fibrosis extraction ratio (FER). These indices have potential in detecting different stages of fibrosis, but studies were small and further testing is needed $[5,6,10]$. One disadvantage of ultrasound imaging is inter-operator variability. Furthermore, measurements are altered by disease processes that affect hepatic blood flow (right sided heart failure, vasoactive medications, post liver transplant). Diffuse fatty infiltration may also interfere with results of hepatic vein waveform and hepatic artery resistance index [14].

Elasticity imaging is now considered a useful technique for tissue characterization. Some methods utilize ultrasound technology, others use magnetic resonance. Transient elastography (TE) measures liver stiffness as a surrogate marker for fibrosis. This utilizes a probe with an ultrasonic transducer that transmits low frequency and low amplitude vibrations that produce shear waves and a pulseecho ultrasound wave that determines the shear wave velocity. This velocity is directly related to liver stiffness. The advantages include a short procedure time (5-15 $\mathrm{min})$, immediate results, good inter-observer consistency, and the ability to perform the procedure at bedside. The disadvantages include less availability and occasional invalid 
Table 1 Ultrasound parameters studied as indirect measurement of liver fibrosis

\begin{tabular}{|c|c|c|c|c|c|c|c|}
\hline Reference & $\begin{array}{l}\text { Year } \\
\text { published }\end{array}$ & $n$ & Population & Test & Biopsy & $\begin{array}{l}\text { Disti } \\
\text { and }\end{array}$ & $\begin{array}{l}\text { nguishes among stages of fibrosis } \\
\text { irrhosis }\end{array}$ \\
\hline $\begin{array}{l}\text { Bolondi } \\
\text { et al. [3] }\end{array}$ & 1991 & 60 & Mixed & Hepatic vein waveform & No & N/a & $\begin{array}{l}\text { Utilized Child-Pugh scoring as } \\
\text { comparison }\end{array}$ \\
\hline $\begin{array}{l}\text { Colli et al. } \\
\text { [4] }\end{array}$ & 1994 & 52 & $\mathrm{HCV}$ & Hepatic vein waveform & Yes & No & \\
\hline $\begin{array}{l}\text { Hirata et al. } \\
\text { [5] }\end{array}$ & 2001 & 43 & $\begin{array}{l}\mathrm{HCV} \\
\text { cirrhosis }\end{array}$ & $\begin{array}{l}\text { Arterio-porto ratio (hepatic artery and portal } \\
\text { vein maximum velocities) }\end{array}$ & Yes & Yes & \\
\hline $\begin{array}{l}\text { Lim et al. } \\
{[6]}\end{array}$ & 2005 & 78 & $\mathrm{HCV}$ & $\begin{array}{l}\text { Hepatic vein transit time with microbubble } \\
\text { tracer Levovist }\end{array}$ & Yes $^{\mathrm{a}}$ & Yes & \\
\hline $\begin{array}{l}\text { Schneider } \\
\text { et al. [7] }\end{array}$ & 2005 & 119 & $\mathrm{HCV}$ & $\begin{array}{l}\text { Portal vein flow velocity, portal vein } \\
\text { undulation, hepatic vein waveform }\end{array}$ & Yes & No & $\begin{array}{l}\text { Portal vein flow was significantly } \\
\text { reduced in cirrhosis versus } \\
\text { non-cirrhosis }\end{array}$ \\
\hline $\begin{array}{l}\text { Weickert } \\
\text { et al. [8] }\end{array}$ & 2005 & 71 & Mixed & Transmission of heart beats en bloc & Yes & $\mathrm{N} / \mathrm{a}$ & $\begin{array}{l}\text { Only compared cirrhosis with } \\
\text { non-cirrhosis }\end{array}$ \\
\hline $\begin{array}{l}\text { Lim et al. } \\
\text { [9] }\end{array}$ & 2006 & 40 & $\mathrm{HCV}$ & $\begin{array}{l}\text { Hepatic vein transit time with microbubble } \\
\text { tracer SonoVue }\end{array}$ & Yes $^{\mathrm{b}}$ & No & \\
\hline $\begin{array}{l}\text { Yamada } \\
\text { et al. [10] }\end{array}$ & 2006 & 79 & $\begin{array}{l}\mathrm{HCV} \\
\text { mixed }\end{array}$ & Fibrosis extraction ratio & Yes & Yes & \\
\hline $\begin{array}{l}\text { Abbattista } \\
\text { et al. [11] }\end{array}$ & 2008 & 69 & Mixed & $\begin{array}{l}\text { Hepatic vein transit time with microbubble } \\
\text { tracer SonoVue }\end{array}$ & Yes & $\mathrm{N} / \mathrm{a}$ & $\begin{array}{l}\text { Only compared cirrhosis with } \\
\text { non-cirrhosis }\end{array}$ \\
\hline $\begin{array}{l}\text { Rocha et al. } \\
\text { [12] }\end{array}$ & 2012 & 50 & $\mathrm{HCV}$ & Portal vein pulsatility index & Yes & N/a & $\begin{array}{l}\text { Only compared no significant } \\
\text { fibrosis with significant fibrosis } \\
\text { in analysis }(\mathrm{F} 2,3,4)\end{array}$ \\
\hline $\begin{array}{l}\text { Salvatore } \\
\text { et al. [13] }\end{array}$ & 2012 & 103 & $\mathrm{HCV}$ & $\begin{array}{l}\text { Hepatic artery resistance index, hepatic vein } \\
\text { waveform }\end{array}$ & No & $\mathrm{N} / \mathrm{a}$ & $\begin{array}{l}\text { Compared with TE and not } \\
\text { biopsy }\end{array}$ \\
\hline
\end{tabular}

${ }^{a}$ Biopsy times were variable and can be over 1 year from time of ultrasound study

b Median time to biopsy was 9.3 months

exams (about 2-16\%). Accurate results require ten valid measurements, a success rate of $>60 \%$, and an IQR of $<30 \%$. Certain situations limit use of TE (ascites and narrow intercostal spaces). Obesity was an initial limiting factor, as the Fibroscan $\mathbf{M}^{\circledR}$ probe did not reach adequate depth; however, newer probes (Fibroscan XL probe ${ }^{\circledR}$ ) claim to overcome the skin to liver capsular distance (SCD). The liver is encapsulated and therefore any space occupying disease process will interfere with measurements (edema, inflammation, cholestasis, congestion, acute hepatitis) $[15,16]$. TE is established in quantifying fibrosis in patients with viral hepatitis $\mathrm{C}$ more so than B. Cutoff values for cirrhosis and significant fibrosis may differ depending on disease etiology, disease prevalence and level of transaminases $[17,18]$.

\section{Comparing Doppler to Elastography}

The study conducted by Lutz et al. [19] in this issue of Digestive Diseases and Sciences utilized ultrasound Doppler technology and compared this to TE using the Fibroscan $\mathrm{M}^{\circledR}$ probe. Patients with a variety of chronic liver diseases were enrolled. They excluded patients with history of congestive heart failure, post transplantation, and decompensated liver disease. No vasoactive medications were taken $24 \mathrm{~h}$ prior to the procedures. They determined the hepatic vein resistance index (HVRI), the diameter of the portal vein, portal flow, hepatic artery resistance index (HARI) and hepatic artery pulsatility index (HAPI). There were three ultrasound operators; however, inter-observer variability was not directly addressed. A liver biopsy and serum studies were obtained during the same session.

The final analysis included 125 patients. The authors found that HVRI decreased and correlated with the stage of fibrosis: F0 $1.42 \pm 0.02, \mathrm{~F} 11.26 \pm 0.05, \mathrm{~F} 21.06 \pm 0.06$, $\mathrm{F} 30.87 \pm 0.08$, and F4 $0.46 \pm 0.12$. Although there was statistical difference between the stages of fibrosis, there was notably no significant difference between F1 and F2, F2 and F3. Furthermore, there was no comment on F0-F1 versus $\geq F 2$, similar to other studies using non-invasive techniques [2]. HARI failed to differentiate significant fibrosis but was significantly elevated in cirrhosis (F4 vs. F0-F3; $p<0.05)$. HAPI failed to correlate with fibrosis. Portal flow and diameter only differentiated cirrhosis. Of note, portal blood flow undulation was significantly reduced in $\geq \mathrm{F} 2$ versus $\mathrm{F} 0$ ( $p<0.05$ ). No correlation was found between HVRI and steatosis or inflammation. 
Detailed TE data analysis for fibrosis was not provided. The authors included mean values $(\mathrm{kPa})$ : F0 $6.0 \pm 0.05$, F1 $9.8 \pm 1.0, \quad F 2 \quad 8.9 \pm 1.9, \quad$ F3 $20.9 \pm 4.9$, and F4 $20.7 \pm 3.8$. Although TE values correlated with inflammation grades $0-3$, the authors did not comment on whether this correlation was significant. After analysis via receiver operating characteristic (ROC) curve, the area under ROC (AUROC) for HVRI was $0.9374 \pm 0.022$ for fibrosis stage $\geq F 2$. The cutoff value was 1.185 with a sensitivity and specificity of 89.66 and $86.32 \%$ respectively. The AUROC for TE was $0.806 \pm 0.055$ for fibrosis stage $\geq F 2$. The cutoff value was $8.05 \mathrm{kPa}$ with a sensitivity and specificity of 74.07 and $69.05 \%$ respectively. The authors concluded that HVRI was a reliable predictor of fibrosis stage $\geq F 2$, was superior to TE and that HVRI could be used as part of the workup and follow up of chronic liver disease.

\section{Strengths and Limitations}

This study serves to demonstrate that fibrosis increases liver stiffness and reduces hepatic vein flow. It is the first study that measured HVRI in comparison with TE and liver histology, and demonstrated the diagnostic value of an inexpensive bedside study in diagnosing significant fibrosis regardless of disease etiology. Although HVRI is a promising tool for diagnosing significant fibrosis, it is not quite ready to replace liver biopsy or other non-invasive models. Because they included a mixed population and did not provide results stratified by disease etiology (HCV, HBV, NASH, etc.), I am still not sure how HVRI performs. It would be interesting to see how TE compared with HVRI broken down by disease etiology. As stated by the authors, subgroup analyses were limited by population size. Because the above limiting factors were not adjusted for, comparisons between HVRI and TE are inconclusive and further larger studies are needed.

Although the authors proposed that HVRI might be used in combination with other tests in diagnosing fibrosis, they did not provide data to support the combined use of HVRI with any other non-invasive biomarker model such as APRI and FIB-4. The omission of laboratory tests, such as liver enzymes (AST, ALT, ALP) and platelet count, limits our interpretation of their results. Furthermore, although they suggest that HVRI can be used to follow patients over time, this was a cross-sectional study and they provide no longitudinal data. Therefore, their results do not support the conclusion that HVRI can be used as a follow-up tool during therapy.

This study appropriately excluded patients who had disease processes that altered Doppler measurements but did not fully address factors that altered TE measurements (ascites, obesity, etc.). Three patients did not have valid TE results due to obesity and were excluded. The average BMI was not reported. They included patients with cholestasis, of which 13 patients had biliary disease and 11 had significant elevations in bilirubin. As these conditions may have been associated with more transient liver disease and not fibrosis per say, they should either have not been included or analyzed separately. In support of this, they compared HVRI and TE values with only the 11 values and did not find correlation. Thirty patients received a diagnosis of NASH and 57 (45\%) patients had significant inflammation on biopsy (which may increase TE values). This study also included 17 toxic hepatopathy patients, which they did not define. This can refer to resolved hepatitis from drugs, alcohol, toxins, etc. The status of chronic liver disease, implying the subsequent development of fibrosis, is questionable in these patients and their inclusion in the final analysis needs clarification.

\section{Conclusion}

In a world where our gold standard also has significant flaws, researchers are faced with a difficult task in developing a test that spans all disease processes, body sizes, and comorbidities. The present study on HVRI added yet another modality to assess fibrosis. Because it does not require additional or new equipment, it may be an attractive alternative to TE. However, until conformational studies are done in larger populations, HVRI cannot be used to measure fibrosis.

Conflict of interest No conflict of interest has been declared by the authors.

\section{References}

1. Rockey DC, Caldwell SH, Goodman ZD, Nelson RC, Smith AD. Liver biopsy. Hepatology. 2009;49:1017-1044.

2. Smith JO, Sterling RK. Systematic review: non-invasive methods of fibrosis analysis in chronic hepatitis C. Aliment Pharmacol Ther. 2009;30:557-576.

3. Bolondi L, Li Bassi S, Gaiani S, et al. Liver cirrhosis: changes of Doppler waveform of hepatic veins. Radiology. 1991;178: 513-516.

4. Colli A, Cocciolo M, Riva C, et al. Abnormalities of Doppler waveform of the hepatic veins in patients with chronic liver disease: correlation with histologic findings. AJR Am J Roentgenol. 1994;162:833-837.

5. Hirata M, Akbar SM, Horiike N, Onji M. Noninvasive diagnosis of the degree of hepatic fibrosis using ultrasonography in patients with chronic liver disease due to hepatitis C virus. Eur J Clin Invest. 2001;31:528-535.

6. Lim AK, Taylor-Robinson SD, Patel N, Eckersley RJ, Goldin $\mathrm{RD}$, Hamilton $\mathrm{G}$, et al. Hepatic vein transit times using a 
microbubble agent can predict disease severity non-invasively in patients with hepatitis C. Gut. 2005;54:128-133.

7. Schneider AR, Teuber G, Kriener S, Caspary WF. Noninvasive assessment of liver steatosis, fibrosis and inflammation in chronic hepatitis C virus infection. Liver Int. 2005;25:1150-1155.

8. Weickert U, Buttmann A, Jakobs R, Schilling D, Eickhoff A, Riemann JF. Diagnosis of liver cirrhosis: a comparison of modified ultrasound and laparoscopy in 100 consecutive patients. J Clin Gastroenterol. 2005;39:529-532.

9. Lim AK, Patel N, Eckersley RJ, et al. Hepatic vein transit time of SonoVue: a comparative study with Levovist. Radiology. 2006; 240:130-135.

10. Yamada H, Ebara M, Yamaguchi T, et al. A pilot approach for quantitative assessment of liver fibrosis using ultrasound: preliminary results in 79 cases. $J$ Hepatol. 2006;44:68-75.

11. Abbattista T, Ridolfi F, Ciabattoni E, et al. Diagnosis of liver cirrhosis by transit-time analysis at contrast-enhanced ultrasonography. Radiol Med. 2008;113:860-874.

12. Rocha HL, Diniz AL, Borges VF, Salomao FC. Assessment of portal venous index as a non-invasive method for diagnosing liver fibrosis in patients with chronic hepatitis C. Arq Gastroenterol. 2012;49:14-18.

13. Salvatore V, Borghi A, Peri E, et al. Relationship between hepatic haemodynamics assessed by Doppler ultrasound and liver stiffness. Dig Liver Dis. 2012;44:154-159.
14. Mohammadinia AR, Bakhtavar K, Ebrahimi-Daryani N, et al. Correlation of hepatic vein Doppler waveform and hepatic artery resistance index with the severity of nonalcoholic fatty liver disease. J Clin Ultrasound. 2010;38:346-352.

15. Cardoso AC, Carvalho-Filho RJ, Marcellin P. Transient elastography in chronic viral hepatitis: a critical appraisal. Gut. 2011; 60:759-764.

16. Cohen EB, Afdhal NH. Ultrasound-based hepatic elastography: origins, limitations, and applications. J Clin Gastroenterol. 2010; 44:637-645.

17. Ogawa E, Furusyo N, Toyoda K, et al. Transient elastography for patients with chronic hepatitis $\mathrm{B}$ and $\mathrm{C}$ virus infection: noninvasive, quantitative assessment of liver fibrosis. Hepatol Res. 2007;37:1002-1010.

18. Sandrin L, Fourquet B, Hasquenoph JM, et al. Transient elastography: a new noninvasive method for assessment of hepatic fibrosis. Ultrasound Med Biol. 2003;29:1705-1713.

19. Lutz HH, Gassler N, Tischendorf FW, Trautwein C, Tischendorf JJ. Doppler ultrasound of hepatic blood flow for noninvasive evaluation of liver fibrosis compared with liver biopsy and transient elastography. Dig Dis Sci. 2012. (Epub ahead of print). doi:10.1007/s10620-012-2153-0. 